\title{
Effects of emodin on the demethylation of tumor-suppressor genes in pancreatic cancer PANC-1 cells
}

\author{
HAO ZHANG $^{1 *}$, LIANG CHEN ${ }^{1 *}$, HE-QI BU ${ }^{2 *}$, QING-JIANG YU ${ }^{1}$, DAN-DAN JIANG ${ }^{1}$, \\ FENG-PING PAN ${ }^{1}$, YU WANG ${ }^{1}$, DIAN-LEI LIU ${ }^{3}$ and SHENG-ZHANG LIN ${ }^{4}$ \\ ${ }^{1}$ Department of Hepatobiliary Surgery, The First Hospital of Jiaxing, Jiaxing, Zhejiang 310012; \\ ${ }^{2}$ Department of Anorectal Surgery, Tongde Hospital of Zhejiang Province, Hangzhou, Zhejiang 310012; \\ ${ }^{3}$ Department of Surgery, Hangzhou Hospital of Traditional Chinese Medicine, Hangzhou, Zhejiang 310003; \\ ${ }^{4}$ Department of Hepatobiliary-Pancreatic Surgery, The First Affiliated Hospital, Zhejiang University \\ School of Medicine, Hangzhou, Zhejiang 310003, P.R. China
}

Received February 5, 2015; Accepted March 24, 2015

DOI: 10.3892/or.2015.3914

\begin{abstract}
Emodin, a natural anthraquinone derivative isolated from Rheum palmatum, has been reported to inhibit the growth of pancreatic cancer cells through different modes of action; yet, the detailed mechanism remains unclear. In the present study, we hypothesized that emodin exerts its antitumor effect by participating in the regulation of the DNA methylation level. Our research showed that emodin inhibited the growth of pancreatic cancer PANC-1 cells in a dose- and time-dependent manner. Dot-blot results showed that $40 \mu \mathrm{M}$ emodin significantly inhibited genomic $5 \mathrm{mC}$ expression in the PANC-1 cells, and mRNA-Seq showed that different concentrations of emodin could alter the gene expression profile in the PANC-1 cells. BSP confirmed that the methylation levels of P16, RASSF1A and ppENK were decreased, while concomitantly the unmethylated status was increased. RT-PCR and western blotting results confirmed that the low expression or absence of expression of mRNA and protein in the PANC-1 cells was re-expressed following treatment with emodin. In conclusion, our study for the first time suggests that emodin inhibits pancreatic cancer cell growth, which may be related to the demethylation of tumor-suppressor genes. The related mechanism may be through the inhibition of methyltransferase expression.
\end{abstract}

Correspondence to: Dr Liang Chen, Department of Hepatobiliary Surgery, The First Hospital of Jiaxing, 1882 Zhong-Huan South Road, Jiaxing, Zhejiang 310012, P.R. China

E-mail: 542393023@qq.com

*Contributed equally

Key words: pancreatic carcinoma, methyltransferase, demethylation, emodin

\section{Introduction}

Pancreatic cancer is a malignant tumor caused by the mutation of normal pancreatic tissues, and $95 \%$ of pancreatic cancers are adenocarcinomas (1). In the US, pancreatic cancer is the fourth highest cause of cancer-related mortality each year, and the eighth highest in the world (2). In China, pancreatic cancer death ranks sixth among cancer-related deaths each year (3). Since the pathogenesis is not clear, there are no effective drugs for the treatment of pancreatic cancer. Currently, surgical resection is the most common treatment for pancreatic cancer. However, there are no convincing results concerning clinically relevant improvements in the quality of life and survival of these patients. Therefore, it is imperative to identify drugs that exhibit low toxicity and are relatively inexpensive.

Epigenetic changes in cancer have gained great attention. Epigenetic modifications mainly include DNA methylation and hydroxymethylation, histone methylation and acetylation, chromatin remodeling, genomic imprinting and RNA interference. DNA methylation is catalyzed by a group of DNA methyltransferase (DNMT) enzymes: mainly DNMT1, DNMT3a and DNMT3b (4). Studies have shown that DNA methylation plays an important role in the occurrence and development of many malignant tumors. In recent years, it has been discovered that under the catalysis of the Tets family, $5 \mathrm{mC}$ is transformed into $5 \mathrm{hmC}$ and $5 \mathrm{fmC}$. The content of $5 \mathrm{hmC}$ in many types of cancer is low, and is closely related to the occurrence and development of melanoma (6).

Studies have found that many tumor-suppressor genes have abnormal methylation in pancreatic cancer, including CDKN1C (7), SPARC (8), P16 (9), RASSF1A (10) and ppENK (11). Methylated tumor-suppressor genes have a different degree of methylation and are not able to express the corresponding mRNAs. Among these tumor-suppressor genes, P16, RASSF1A and ppENK have been extensively studied. Ueki et al (11) and Fukushima et al (12) found an increase of more than $90 \%$ of ppENK gene methylation level in pancreatic cancer. Schutte et al (13) reported that of $95 \%$ of P16 gene inactivation, $15 \%$ was related with methylation in 
pancreatic cancer. Moore et al (14) reported that the P16 gene was methylated in $27 \%$ of pancreatic cancer cells. Dammann et al (10) reported that after culturing various pancreatic cells with the demethylation drug 5-Aza-CdR, the RASSF1A gene methylation level was increased in $64 \%$ of primary pancreatic ductal cell carcinoma, $83 \%$ of pancreatic endocrine tumors and $88 \%$ of pancreatic cancer cell lines. P16 and RASSF1A were re-expressed at various degrees to play an antitumor function.

Currently, the most commonly used demethylation drugs are 5-azacytidine (5-AzaC) and decitabine (5-aza-2-deoxycytidine; 5-Aza-CdR), which are two different types of nucleoside analogs (15). In the US, 5-AzaC and 5-aza-2'-deoxycytidine have been approved by the Food and Drug Administration (FDA). These drugs are mainly used for the treatment of hematological malignancies. Other approved demethylation drugs include zebularine (16), DHAC (17), hydralazine (18), selenite (19), RG108 (20) and arsenic trioxide (21). However, clinical trials have reported that the demethylation effects of certain drugs are not specific. Genomic hypomethylation was found to occur when the drug concentration was too high, and side effects, such as drug toxicity and inhibition of bone marrow, limit its application in the clinical treatment of tumors. The development of a demethylation drug with strong specificity, high safety and low toxicity has become one of the important tasks in tumor treatment.

In recent years, Chinese herbal medicines have been recognized as having antitumor efficacy. Emodin (1,3,8-trihydroxy-6-methyl anthraquinone), one such Chinese herbal medicine, has extensive pharmacological effects such as immune regulation (22), and antibacterial (23), ant-inflammatory and antitumor activities (24). Liu et al (25) reported that emodin inhibits pancreatic cancer cell growth through different modes of action, but the detailed mechanism remains unclear. Studies have found that curcumin (26) and epidermal catechins (EGCG) (27) exert similar antitumor efficacy through demethylation. Therefore, we hypothesized that emodin may exert its antitumor effect though participating in the regulation of the DNA methylation level.

\section{Materials and methods}

Chemicals and reagents. Emodin (purity $\geq 98 \%$ ) and 5-AzaCdR were both purchased from Sigma (St. Louis, MO, USA). Emodin was dissolved in dimethyl sulfoxide (DMSO) to create a stock solution at a concentration of $10 \mathrm{mmol} / \mathrm{l}$ and was stored at $-70^{\circ} \mathrm{C}$. The DMSO concentration was maintained below $0.1 \%$ in all of the cell cultures and did not exert any detectable effect on cell growth or cell death. The Cell Counting Kit-8 (CCK-8) was purchased from Gibco. A cell and tissue genomic DNA extraction kit was purchased from Fastagen Biotech (Shanghai, China). The EpiTect ${ }^{\circledR}$ Bisulfite and EpiTect ${ }^{\circledR}$ MSP kits were purchased from Qiagen. The RNA extraction kit was purchased from Tiangen (Beijing, China). The antibodies, anti-RASSF1a and anti-ppENK were purchased from Abcam. The anti-P16/INK4a antibody and anti- $\beta$-actin were purchased from Epitomics.

Cell line and culture. Human pancreatic cancer cell line PANC-1 was obtained from the American Type Culture
Collection (ATCC; Manassasas, VA, USA). The cells were cultured in Dulbecco's modified Eagle's medium (DMEM) supplemented with $10 \%$ FBS, $100 \mathrm{U} / \mathrm{ml}$ penicillin and $100 \mu \mathrm{g} / \mathrm{ml}$ streptomycin. Cells were maintained at $37^{\circ} \mathrm{C}$ in a humidified atmosphere of $5 \% \mathrm{CO}_{2}$. The medium was changed every 2-3 days, and the cells were subcultured when confluency reached $70-80 \%$ in $0.25 \%$ trypsin at $37^{\circ} \mathrm{C}$.

Cell proliferation assay. Cell survival was determined using CCK-8. Briefly, logarithmic phase PANC-1 cells were plated in 96-well culture plates $\left(\sim 5 \times 10^{3}\right.$ cells/well). After $24 \mathrm{~h}$ of incubation, the cells were treated with the vehicle alone (0.1\% DMSO) and various concentrations $(10,20,40$ and $80 \mu \mathrm{M})$ of emodin, followed by a 24-, 48- and 72-h cell culture. Each group had 6 wells. A total of $10 \mu \mathrm{lCCK}-8$ was added to each well $1 \mathrm{~h}$ before the end of the incubation period. The absorbance at $450 \mathrm{~nm}$ was read using the Bio-Tek ELx800 absorbance microplate reader. The experiment was repeated 3 times. The degree of cellular inhibition by each drug was calculated by the following formula: Relative $\%$ inhibition $=1-($ dosing absorbance - blank absorbance)/(control absorbance - blank absorbance) x $100 \%$.

Dot-blot assay. The PANC-1 cells were treated with emodin $(0,10,20$ and $40 \mu \mathrm{M})$ and 5-Aza-CdR $(1 \mu \mathrm{M})$ for $72 \mathrm{~h}$. The control cells were treated with $0.1 \%$ DMSO only. The total DNA was isolated from the cultured cells using the cell/tissue genomic DNA extraction kit according to the manufacturer's instructions. The concentrations of DNA were determined by fluorometry using the Qubit ${ }^{\circledR}$ dsDNA HS kit and fluorometer (both from Invitrogen). The procedure for the dot-blot assay was performed with reference to a previous study (28).

$m R N A$-sequence. The PANC-1 cells were treated with emodin $(0,10,20$ and $40 \mu \mathrm{M})$ and 5-Aza-CdR $(1 \mu \mathrm{M})$ for $72 \mathrm{~h}$. The control cells were treated with $0.1 \%$ DMSO only. The cells were collected and sent to Major Biotechnology Company (Shanghai, China), where the mRNA-seq was analyzed.

Bisulfite sequencing PCR (BSP). The PANC-1 cells were treated with emodin $(0,10,20$ and $40 \mu \mathrm{M})$ and 5-Aza-CdR $(1 \mu \mathrm{M})$ for $72 \mathrm{~h}$. The control cells were treated with $0.1 \%$ DMSO only. Genomic DNA was extracted using the cell/ tissue genomic DNA extraction kit according to the manufacturer's instructions. When the DNA was concentrated to $1 \mu \mathrm{g}$, bisulfite modification of genomic DNA was performed using the EpiTect ${ }^{\circledR}$ Bisulfite kit. The sequences of the methylationspecific primers for P16, RASSF1A and ppENK are shown in Table I. Bisulfite-modified DNA (4 $\mu 1)$, methylation-specific primers $(3 \mu \mathrm{l}), 2 \mathrm{X}$ Taq PCR Master Mix (12.5 $\mu \mathrm{l})$ and DEPC- $\mathrm{H}_{2} \mathrm{O}(5.5 \mu \mathrm{l})$ were added to achieve a final volume of $25 \mu \mathrm{l}$. PCR amplification conditions were as follows: $95^{\circ} \mathrm{C}$ for $5 \mathrm{~min}, 94^{\circ} \mathrm{C}$ for $30 \mathrm{sec}$, annealing for $45 \mathrm{sec}$, and extension at $72^{\circ} \mathrm{C}$ for $45 \mathrm{sec}$; a total of 40 cycles; followed by a final extension at $72^{\circ} \mathrm{C}$ for $10 \mathrm{~min}$. A total of $10 \mu \mathrm{l}$ of the PCR product was separated on a $2 \%$ agarose gel electrophoresis, and the results were photographed. BSP products were extracted from agarose gel, then purified and sequenced (ShangHai Maipu Biotechnology Co., Ltd., China). The methylation of the sample was analyzed using BiQ Analyzer software. 
Table I. Primer sequences for PCR and bisulfite sequencing.

\begin{tabular}{|c|c|c|}
\hline Genes & $\begin{array}{l}\text { Primer pairs } \\
\qquad\left(5^{\prime} \rightarrow 3^{\prime}\right)\end{array}$ & $\begin{array}{c}\text { Product } \\
\text { size (bp) }\end{array}$ \\
\hline \multirow[t]{2}{*}{$\mathrm{P} 16$} & F: GCCGATCCAGGTCATGATGAT & \\
\hline & R: GCATCTATGCGGGCATGGTTA & 300 \\
\hline \multirow[t]{2}{*}{ RASSF1A } & F: TGGGGAGGTGAACTGGGAC & \\
\hline & R: ACACGGCACGCACTTGG & 217 \\
\hline \multirow[t]{2}{*}{ ppENK } & F: GCGGTTCCTGACACTTTGC & \\
\hline & R: GGGTGCTGGTGCCATCTT & 245 \\
\hline \multirow[t]{2}{*}{ DNMT1 } & F: GACCCATCTCTTGAAGGTGGTGTT & \\
\hline & R: CCTCGTCATAACTCTCCACCTGCT & 164 \\
\hline \multirow[t]{2}{*}{ DNMT3a } & F: AGGTGGACCGCTACATTGCC & \\
\hline & R: GAGATGTCCCTCTTGTCACTAACG & 143 \\
\hline \multirow[t]{2}{*}{$\mathrm{P} 16$} & BS-F: TTGTTGTTTAGGTTGGAGTGTAGTG & \\
\hline & BS-R: TCAAAAACATATATTAATAACAACCATCAA & 256 \\
\hline \multirow[t]{2}{*}{ ppENK } & BS-F: AAAGAGTTTTTGGAAATAGGGGATA & \\
\hline & BS-R: CATCAACAATTTCCCACTAAAAAAT & 241 \\
\hline \multirow[t]{2}{*}{ RASSF1A } & BS-F: GTATGTAAGGGTTGGATGTGTAGAGA & \\
\hline & BS-R: CCCCAAATAAAАTCTCCACAAAАATC & 298 \\
\hline
\end{tabular}

F, forward; R, reverse.

Real-time PCR. The PANC-1 cells were treated with emodin $(0,10,20$ and $40 \mu \mathrm{M})$ and 5-Aza-CdR $(1 \mu \mathrm{M})$ for $72 \mathrm{~h}$. The control cells were treated with $0.1 \%$ DMSO only. Total RNA was isolated from the cells using the TRIzol reagent (Invitrogen) according to the manufacturer's instructions. For reverse transcriptase analysis, $1 \mu \mathrm{g}$ of total RNA was reversely transcribed in a $20 \mu \mathrm{l}$ volume using RevertAid ${ }^{\mathrm{TM}}$ First Strand cDNA Synthesis kit (Fermentas). Real-time PCR amplification with $1 \mu \mathrm{l}$ of the reverse transcriptase reaction mixture was performed with SYBR Green Real-Time PCR Master Mix-Plus (Toyobo, Japan). The initial denaturation step was $95^{\circ} \mathrm{C}$ for $60 \mathrm{sec}$ followed by 40 cycles of amplification at $95^{\circ} \mathrm{C}$ for $15 \mathrm{sec}, 60^{\circ} \mathrm{C}$ for $15 \mathrm{sec}$, and $72^{\circ} \mathrm{C}$ for $45 \mathrm{sec}$. All samples were performed in triplicate, and the relative amount of the target gene was normalized to GAPDH. The primers are listed in Table I.

Western blot analysis. The PANC-1 cells were treated with emodin $(0,10,20$ and $40 \mu \mathrm{M})$ and 5-Aza-CdR $(1 \mu \mathrm{M})$ for $72 \mathrm{~h}$. The control cells were treated with $0.1 \%$ DMSO only. Total proteins were extracted from the cells using cell lysis buffer (20 mmol/l Tris- $\mathrm{HCl} \mathrm{pH} \mathrm{7.5,} 150 \mathrm{mmol} / \mathrm{l} \mathrm{NaCl}, 1 \mathrm{mmol} / \mathrm{l}$ $\mathrm{Na}_{2}$ EDTA, $1 \mathrm{mmol} / 1$ EGTA, $1 \%$ Triton, $2.5 \mathrm{mmol} / 1$ sodium pyrophosphate, $1 \mathrm{mmol} / 1 \beta$-glycerophosphate, $1 \mathrm{mmol} / 1$ $\mathrm{Na}_{3} \mathrm{VO}_{4}, 1 \mu \mathrm{g} / \mathrm{ml}$ leupeptin, and $\left.1 \mathrm{mmol} / \mathrm{l} \mathrm{PMSF}\right)$. After centrifugation at $14,000 \mathrm{x}$ g for $10 \mathrm{~min}$ at $4^{\circ} \mathrm{C}$, the supernatant was collected and the protein concentration was determined using the BCA protein assay kit according to the manufacturer's instructions. The protein lysates $(20-\mu \mathrm{g}$-lane) were separated on $12 \%$ SDS polyacrylamide gel and transferred onto a nitrocellulose membrane. Each membrane was blocked with $5 \%$ skim milk and then incubated with the indicated primary antibodies against P16, RASSF1A, ppENK and $\beta$-actin over- night at $4^{\circ} \mathrm{C}$. Subsequently, the membrane was incubated with the secondary antibodies, goat anti-rabbit and anti-mouse IgG conjugated with HRP, for $1 \mathrm{~h}$ at room temperature, and the formed immunocomplex was visualized by enhanced chemiluminescence reagent and exposed to X-ray film. Quantitative data are expressed as a percentage of the mean \pm standard deviation (SD) of the relative levels of the objective protein and control $\beta$-actin of each group of cells from three independent experiments.

Statistical analysis. All results were repeated in at least three separate experiments. The data are expressed as the mean \pm SD. Statistical comparisons were conducted using one-way analysis of variance, which revealed significant differences between groups, and the Student's t-test which revealed significant differences between two sample means. Statistical analyses were carried out using SPSS version 17.0 software (SPSS Inc., Chicago, IL, USA). P<0.05 was considered to indicate a statistically significant difference.

\section{Results}

Effect of emodin on PANC-1 cell proliferation. To investigate the effect of emodin on cell growth, PANC-1 cells were cultured with $0,10,20,40$ and $80 \mu \mathrm{M}$ emodin for 24, 48 and $72 \mathrm{~h}$. Cell proliferation was determined by the CCK- 8 assay. As demonstrated in Fig. 1, emodin was shown to inhibit the growth of the cells in a dose- and time-dependent manner. This result was similar with a previous study (29). The inhibition rate of emodin at a concentration of $40 \mu \mathrm{M}$ for $72 \mathrm{~h}$ was $49.4 \%$, while the inhibition rate of emodin at a concentration of $80 \mu \mathrm{M}$ for $72 \mathrm{~h}$ reached $64.4 \%$. Since the methylation efficiency of drugs is usually exerted under the appropriate low 


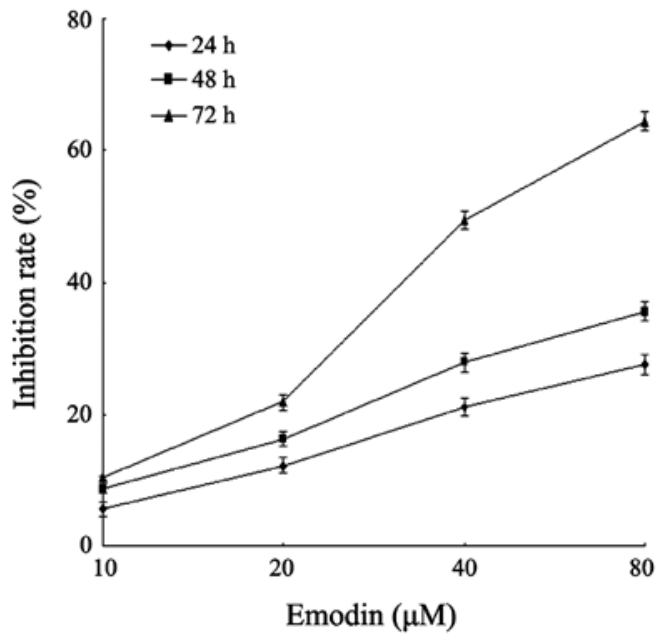

Figure 1. Effects of emodin on the inhibition of the growth of pancreatic cancer (PANC-1) cells in vitro. PANC-1 cells were treated with the vehicle or 10, 20, 40 and $80 \mu \mathrm{M}$ emodin for 24,48 and $72 \mathrm{~h}$. The cell proliferation inhibition rates were determined by the Cell Counting Kit-8 (CCK-8) assay, and are presented as the means \pm SD from three independent experiments.

drug concentration, emodin at a concentration of 10,20 and $40 \mu \mathrm{M}$ was used for the following experimental research.

Emodin decreases the level of genome $5 \mathrm{mC}$, but has no significant effect on $5 \mathrm{hmC}$. To determine the effects of emodin on the genomic DNA methylation level in the PANC-1 cells, a dot-blot assay was performed. As shown in Fig. 2, emodin at a concentration of $40 \mu \mathrm{M}$ and $1 \mu \mathrm{M}$ 5Aza-CdR significantly reduced the $5 \mathrm{mC}$ level when compared with the level in the control group. However, there were no significant differences in $5 \mathrm{hmC}$ levels. The levels of $5 \mathrm{hmC}$ were slightly decreased by emodin at concentrations of 10 and $20 \mu \mathrm{M}$, but the effect was not obvious. To further confirm this result, the effects of emodin on gene expression profiles were detected by mRNASeq. As shown in Fig. 3, different concentrations of emodin promoted differences between changes in the gene expression profiles. The number of differentially expressed genes was also increased in a dose-dependent manner. In each group, the number of downregulated genes was higher than the upregulated genes. For example, in the emodin $(40 \mu \mathrm{M})$ vs the control group, the expressed genes were mainly concentrated in the KEGG pathway which was closely related to tumor pathways such as cell cycle, p53 signaling, pathways in cancer and apoptosis, cell division, DNA metabolic processes and regulation of cell death. The data suggest that emodin treatment has significant effects on gene expression, and plays an important role in regulating metabolic processes such as cell differentiation and proliferation.

Pyrophosphate sequencing PCR $(B S P)$. In order to verify the differential expression of gene methylation after emodin treatment, BSP was used to detect the methylation levels of P16, RASSF1A and ppENK in the promoter region. As shown in
A

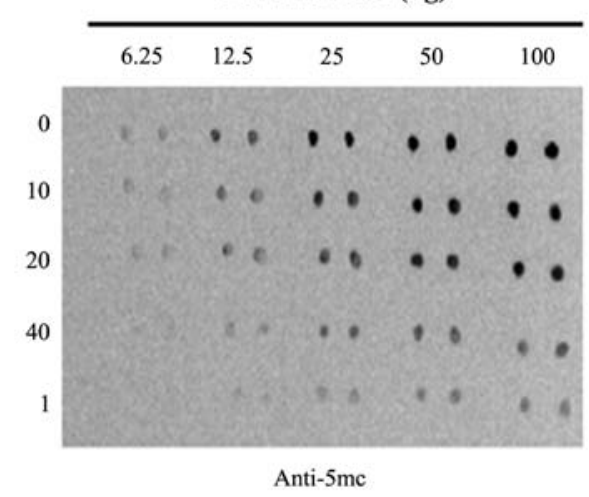

B

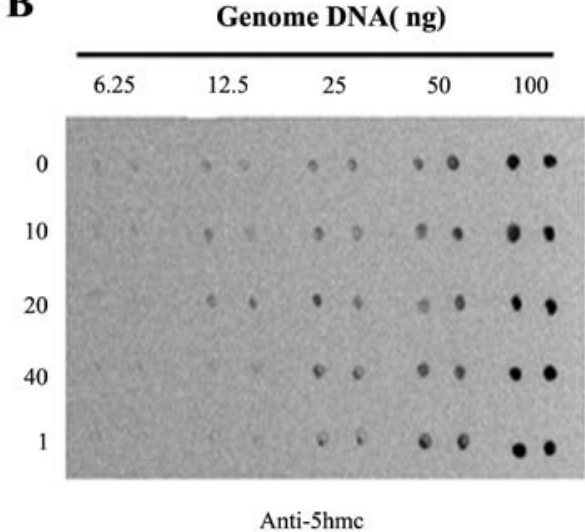

C

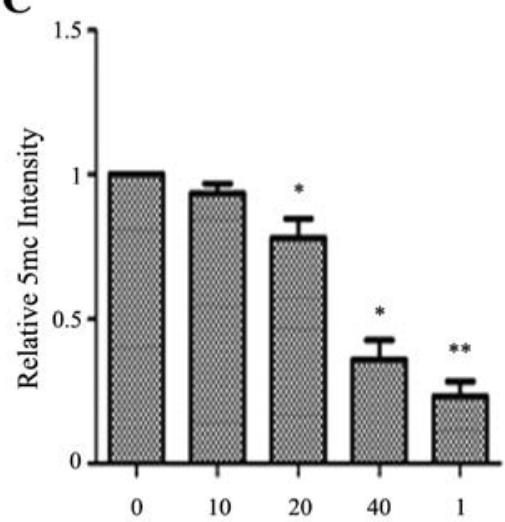

D

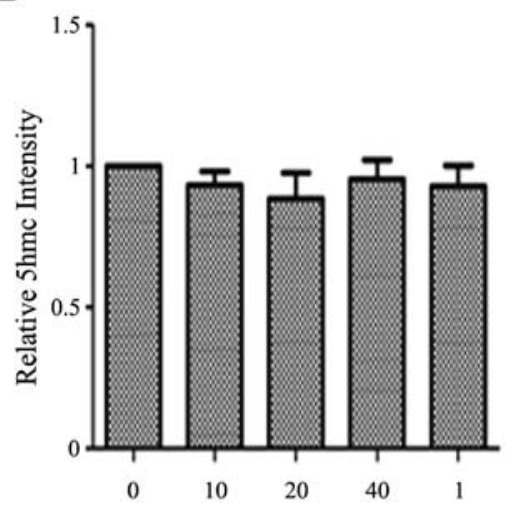

Figure 2. Effect of emodin on the levels of genome $5 \mathrm{mC}$ and $5 \mathrm{hmC}$ in PANC-1 cells. The PANC-1 cells were treated with emodin $(0,10,20$ and $40 \mu \mathrm{M})$ and 5-Aza-CdR $(1 \mu \mathrm{M})$ for $72 \mathrm{~h}$, and the levels of $5 \mathrm{mC}$ and $5 \mathrm{hmC}$ were detected by dot-blot assay. (A) Treatment with $40 \mu \mathrm{M}$ emodin and $1 \mu \mathrm{M} 5 \mathrm{Aza}-\mathrm{CdR}$ significantly reduced the expression of 5mC. (B) Emodin $(0,10,20$ and $40 \mu \mathrm{M})$ and $1 \mu \mathrm{M}$ 5-Aza-CdR had no significant effect on the expression of 5hmC. (C) and (D) Quantification was performed by calculating the ratio of the experimental value to the control. ${ }^{*} \mathrm{P}<0.05,{ }^{* *} \mathrm{P}<0.01$. 
A

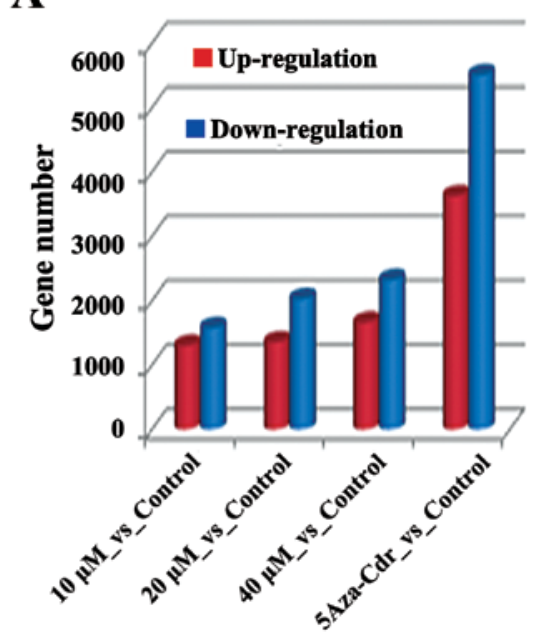

B

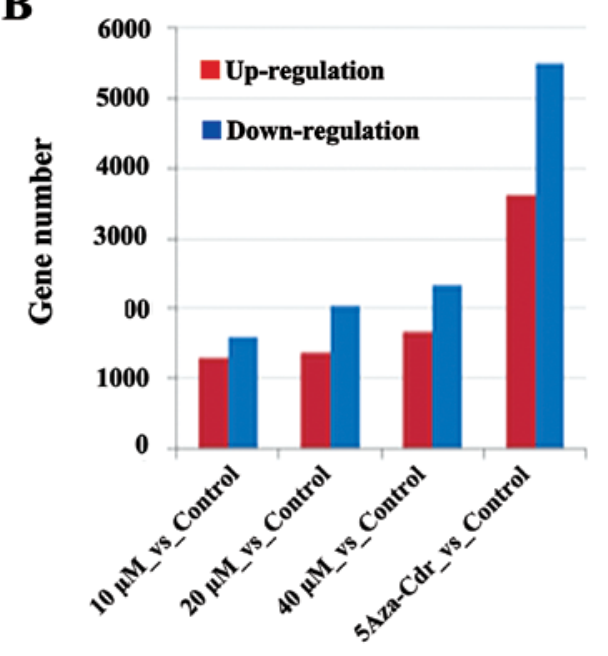

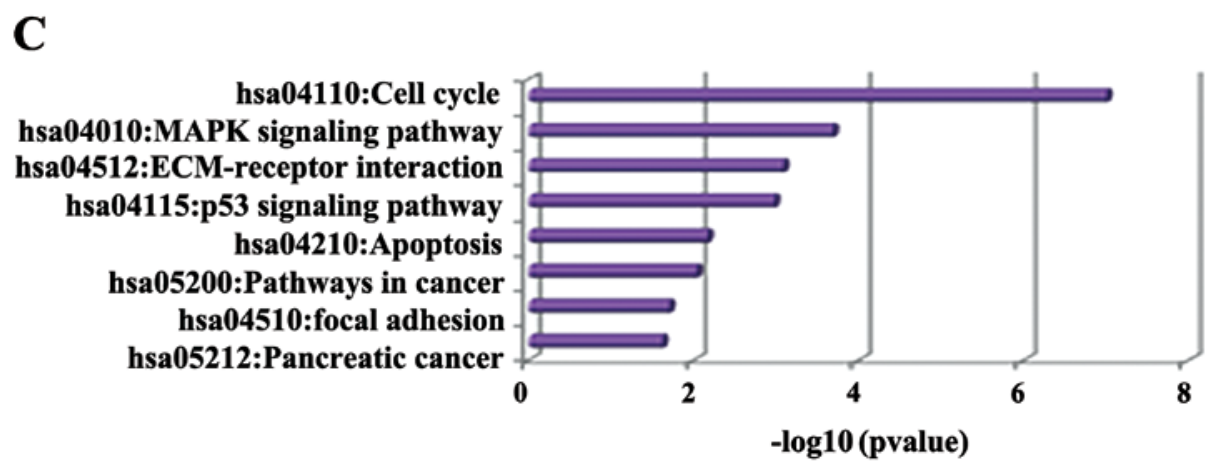

Figure 3. Effect of emodin on the gene expression profiles in PANC-1 cells. (A and B) mRNA-seq was used to detect the number of differentially expressed genes $(\mathrm{P}<0.05$ and upregulation/downregulation of 2 -fold). (C) Expression of various genes in the $40 \mu \mathrm{M}$ emodin vs. control group was analyzed using the DAVID software in the KEGG metabolism pathway.

Fig. 4, treatment with emodin led to different degree of demethylation levels of P16, ppENK and RASSF1A in the promoter regions. Scopes of P16, ppENK, RASSF1A gene sequencing were respectively composed of 17,11 and $36 \mathrm{CpG}$ islands, 10 of which were randomly selected to clone and sequence. After treatment of PANC-1 cells with various concentrations of emodin $(0,10,20$ and $40 \mu \mathrm{M})$ and 5-Aza-CdR $(1 \mu \mathrm{M})$ for $72 \mathrm{~h}$, the methylation rates of the P16 gene were 93.5, 71.8, 59.4 and $33.5 \%$, respectively. While the methylation rate in the 5-Aza-CdR group was decreased to $25 \%$. The effect in the 5-Aza-CdR group was stronger than that in the emodin-treated group. The methylation rates of the ppENK gene were 86.4 , 82.7, 67.3 and 52.7\%, respectively, while that in the 5-Aza-CdR group was $39.1 \%$. The methylation rates of the RASSF1A gene were $65.3,60,27.2$ and $16.4 \%$, respectively, while that in the 5-Aza-CdR group was $15.3 \%$. These results demonstrated that emodin reduced the methylation levels of P16, RASSF1A and $\mathrm{ppENK}$ in the promoter region in pancreatic cancer cells.

Effects of emodin on $m R N A$ and protein expression of P16, RASSF1A, ppENK and DNA methyltransferases (DNMTs). The levels of methylation of P16, RASSF1A and ppENK in the promoter region were decreased in the PANC-1 cells. However, whether the transcription and protein levels were affected in the emodin-treated PANC-1 cells was unknown.
Thus, we investigated the mRNA and protein expression of P16, RASSF1A, ppENK and DNMTs. As shown in Fig. 5, emodin increased the mRNA expression levels of P16, RASSF1A and ppENK in a dose-dependent manner. 5-AzaCdR also increased the mRNA expression levels of P16, RASSF1A and ppENK. The effect was stronger than that of emodin. As shown in Fig. 6, emodin increased the protein expression levels of P16, RASSF1A and ppENK in a dosedependent manner. 5-Aza-CdR also increased the protein expression levels of P16, RASSF1A and ppENK. The effect was stronger than that of emodin. In Figs. 5B and 6, while emodin decreased the mRNA and protein expression of methyltransferase DNMT1 and DNMT3a, it had no effect on DNMT3b (data not shown). The results suggest that emodin may decrease overall genomic methylation levels by the downregulation of DNMT1 and DNMT3a at the transcription and protein levels, thereby affecting the transcriptional level of the whole genome, upregulating the mRNA and protein levels of the tumor-suppressor genes, P16, RASSF1A and ppENK, and consequently inhibiting tumor growth.

\section{Discussion}

The incidence of pancreatic cancer is increasing yearly, and the fatality rate is high. According to reports in 2008, 37,680 
$\mathbf{A}$

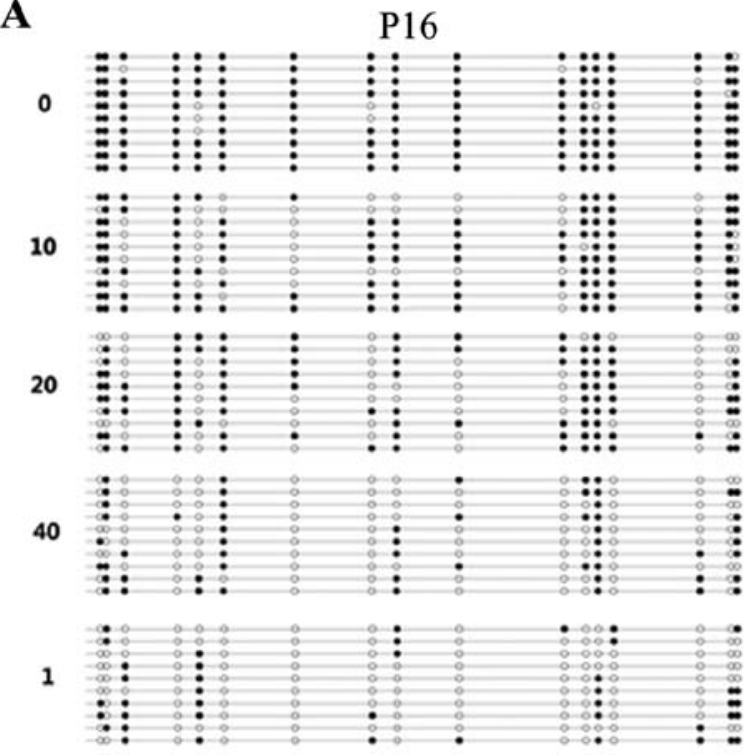

C

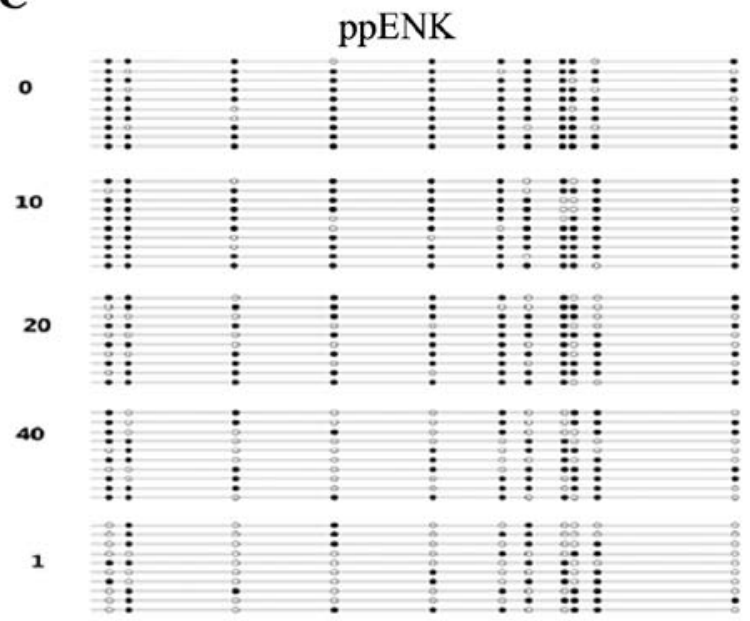

B

RASSFIA

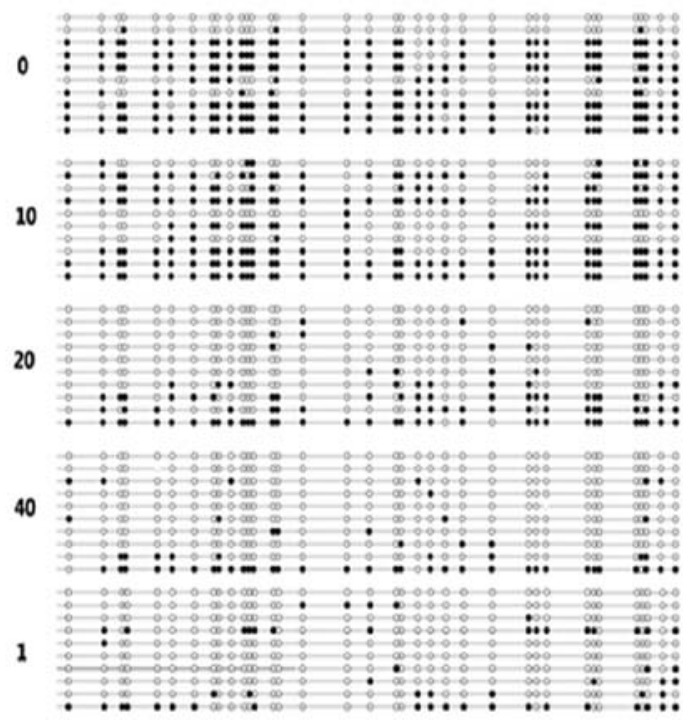

D

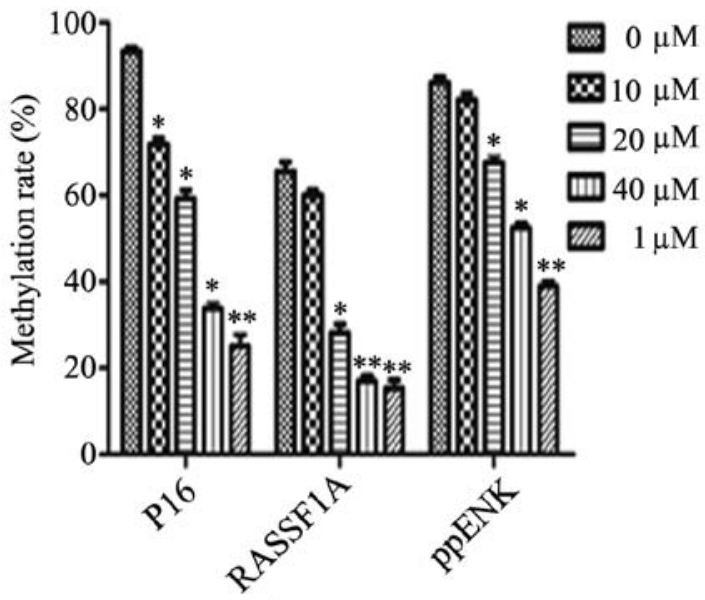

Figure 4. Effect of emodin on the methylation levels of P16, RASSF1A and ppENK in the promoter region in the PANC-1 cells. (A-C) The PANC-1 cells were treated with emodin $(0,10,20$ and $40 \mu \mathrm{M})$ and 5-Aza-CdR $(1 \mu \mathrm{M})$ for $72 \mathrm{~h}$, and the methylation levels of P16, RASSF1A and ppENK in the promoter region were detected by BSP. (D) The methylation rates $(\%)$ are presented as the mean $\pm \mathrm{SD}$ of three independent experiments. ${ }^{*} \mathrm{P}<0.05$, ${ }^{* *} \mathrm{P}<0.01$. Black circles represented methylation, blank circles represented unmethylation.

new patients in the US were diagnosed with pancreatic cancer and 34,290 of them $(91 \%)$ succumbed to the disease (30). The pathogenesis of pancreatic cancer remains unclear and discovering a treatment for this cancer has been a challenge. Emodin has shown curative effects on pancreatic cancer in the clinic. Emodin was found to trigger apoptosis in cancer pancreatic cells (31), to inhibit the formation of new vessels (29) and to improve the resistance to gemcitabine in pancreatic cancer cells (30). However, the specific mechanisms of these curative effects remain unclear. Our data showed that emodin affected the whole genome expression by demethylation, which especially decreased methylation levels of the tumor-suppressor genes P16, RASSF1A and ppENK, thus playing an important role in cancer treatment.

In the present study, the data indicated that varying concentrations of emodin effectively inhibited the proliferation of the PANC-1 cell line at different time points. When PANC-1 cells were treated with $80 \mu \mathrm{M}$ emodin for $72 \mathrm{~h}$, there were significant changes in the growth inhibition rate and the cell morphology, which is consistent with previous literature (29). Notably, when PANC-1 cells were treated with $40 \mu \mathrm{M}$ emodin for $72 \mathrm{~h}$, a decrease in the growth inhibition rate was noted, but no significant changes in the cell morphology were noted. Therefore, emodin at concentrations of $0,10,20$ and $40 \mu \mathrm{M}$ were selected for the experiments. Our results revealed that emodin caused various degrees of demethylation of tumor-suppressor genes P16, RASSF1A and ppENK in PANC-1 cells. Methylation is often the cause of tumor-suppressor gene inactivation, and its expression was found to be inversely proportional to the density of $\mathrm{CpG}$ island methylation. Low levels of methylation caused a 67-90\% inactivation of gene expression, while methylation of high density $\mathrm{CpG}$ islands completely extinguished gene expression (32). PCR also confirmed that emodin caused the re-expression of P16, RASSF1A and ppENK inactivated 

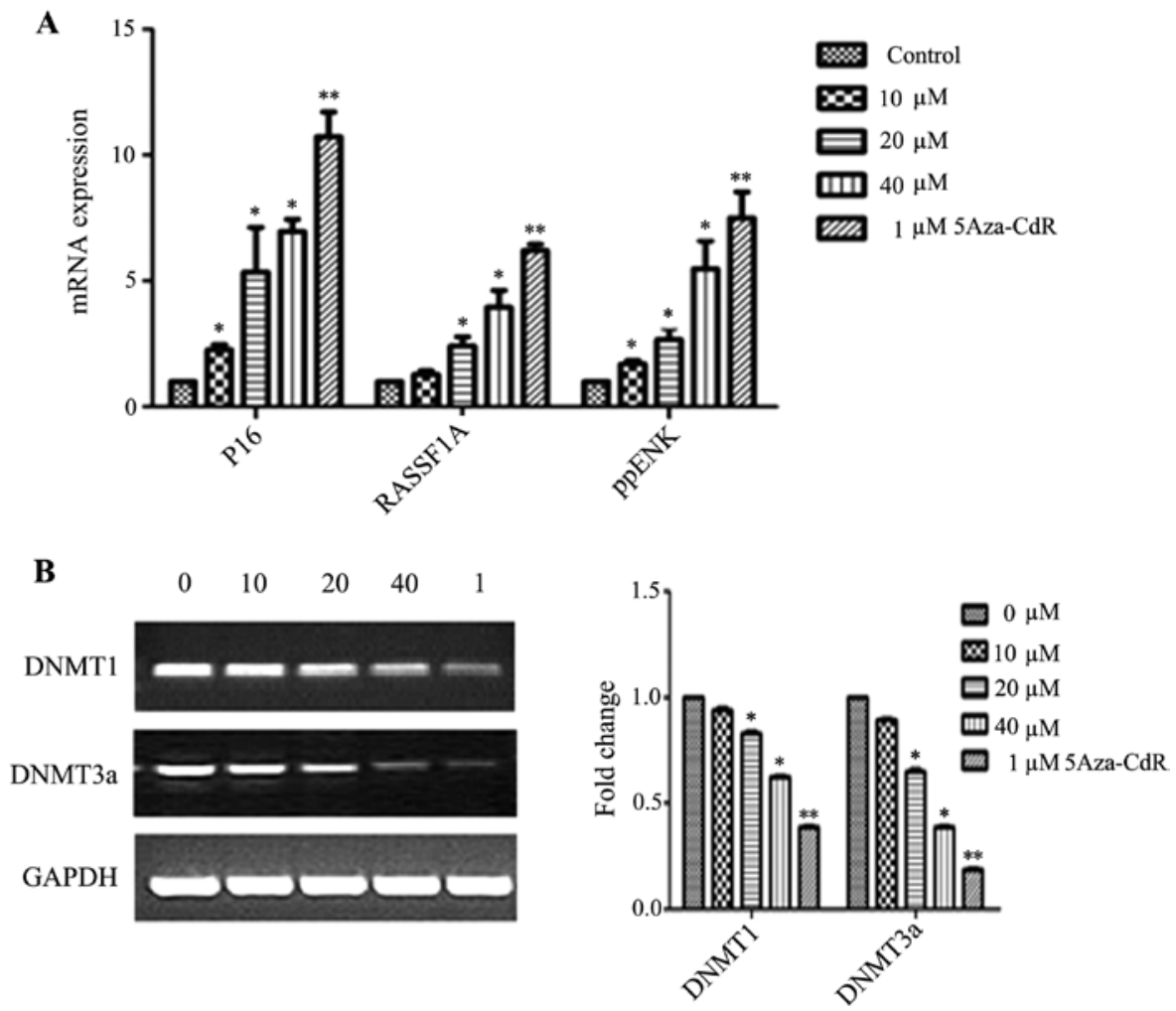

Figure 5. Effects of emodin on the mRNA expression of P16, RASSF1A, ppENK, DNMT1 and DNMT3a in the PANC-1 cells. (A) RT-PCR analysis showed that mRNA expression levels of P16, RASSF1A and ppENK were upregulated. (B) RT-PCR analysis showed that mRNA expression levels of DNMT1 and DNMT3a were downregulated. The effect of emodin was weaker than that of 5-Aza-CdR in the above experiments. ${ }^{*} \mathrm{P}<0.05,{ }^{* *} \mathrm{P}<0.01$.
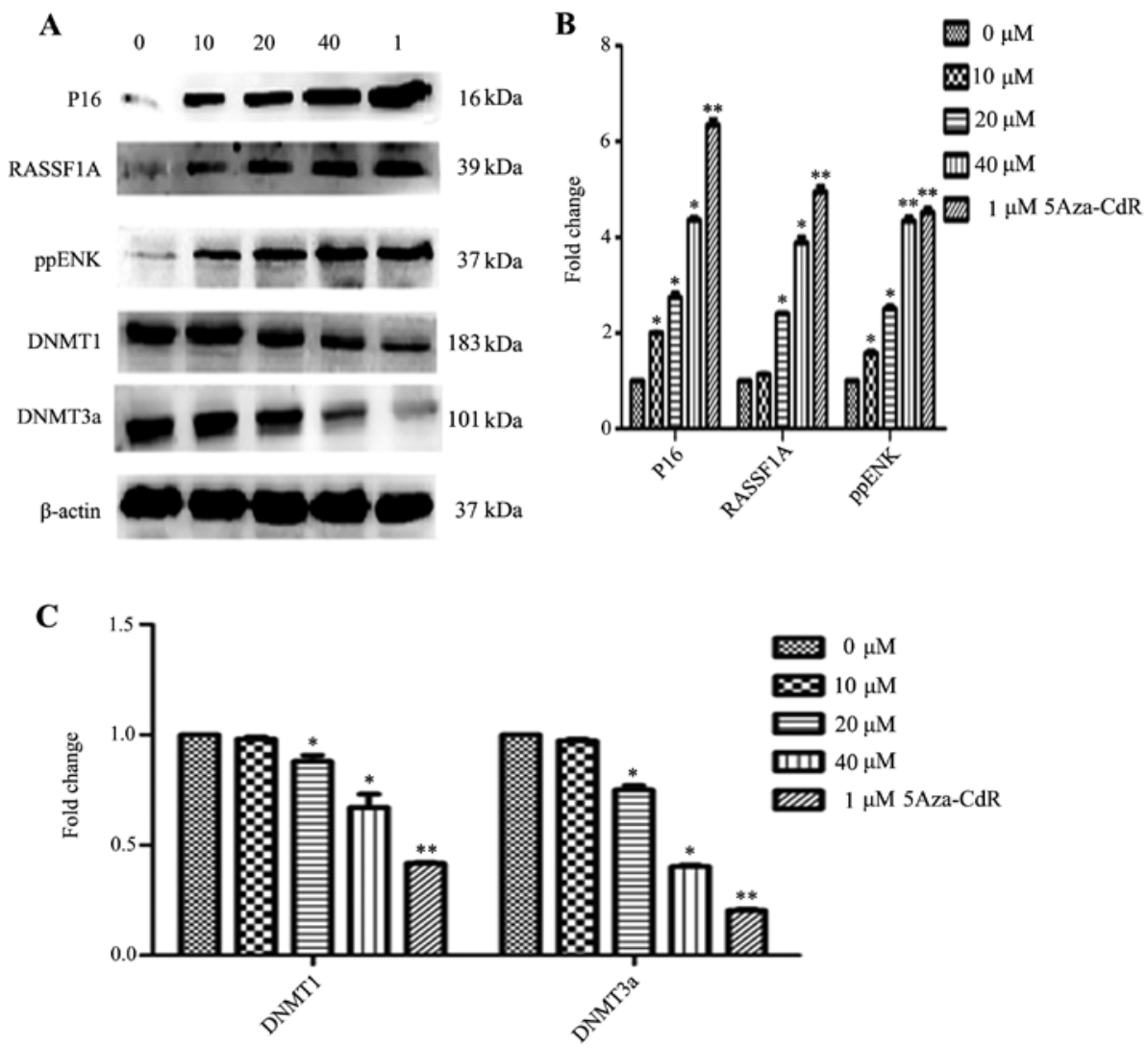

Figure 6. Effects of emodin on the protein expression levels of P16, RASSF1A, ppENK, DNMT1 and DNMT3a in the PANC-1 cells. (A) Protein expression levels were detected by western blot analysis. Protein expression levels of P16, RASSF1A and ppENK were upregulated, while protein expression levels of DNMT1 and DNMT3a were downregulated. The effect of emodin was weaker than that of 5-Aza-CdR in the above experiments. (B and C) The quantification was performed assigning a value of 1 to the control group. The results obtained from three separate experiments are expressed as mean $\pm \mathrm{SD}$. "P<0.05, ${ }^{* * *} \mathrm{P}<0.01$. 
by methylation, and whose expression levels increased in a dose- and time-dependent manner. The results of the western blot analysis further confirmed our research, which provides further evidence that emodin causes the demethylation of tumor-suppressor genes in PANC-1 cells.

In order to further investigate the role of emodin in the demethylation at the epigenetic level in PANC-1 cells, 5-Aza-CdR, which was proven to have demethylation effects in clinical trials, was used in the present study. The results showed that 5-Aza-CdR significantly reduced the methylation levels of the tumor-suppressor genes P16, RASSF1A and ppENK by enhancing the expression of mRNA and protein. Although emodin also plays a demethylation role in PANC-1 cells, the effect was weaker than that of 5-Aza-CdR. In vivo, the methylation was mainly catalyzed by methyltransferases (DNMT1, DNMT3a and DNMT3b). There are two ways to demethylate tumor-suppressor genes: inhibition of methyltransferase activity and reduction in methyltransferase expression. RT-PCR and western blot analysis showed that both $40 \mu \mathrm{M}$ emodin and $1 \mu \mathrm{M}$ 5-Aza-CdR significantly reduced the expression of DNMT1 and DNMT3a, suggesting that demethylation of emodin may be linked with the inhibition of methyltransferase expression. Our study confirmed that emodin caused a certain degree of demethylation in the tumor-suppressor genes P16, RASSF1A, ppENK in the PANC-1 cells. However, it remains to be discovered whether emodin plays a role in the demethylation of different suppressor genes in other pancreatic cancer cell lines. In addition, whether emodin enhances the demethylation of 5-Aza-CdR warrants further research.

The methylation of DNA CpG islands $(5 \mathrm{mC})$ plays an integral role in gene transcriptional silencing, genomic imprinting and $\mathrm{X}$ chromosome inactivation. Currently, $5 \mathrm{hmC}$ is the main focus of research. There are 10 to 11 translocation enzymes which catalyze the oxidation of $5 \mathrm{mC}$ to produce $5 \mathrm{hmC}$; the prominent translocation enzymes include TET1, TET2 and TET3 (32). The specific function of $5 \mathrm{hmC}$ is not very clear; $5 \mathrm{hmC}$ is considered to be an intermediate from $5 \mathrm{mC}$ to $5 \mathrm{C} \mathrm{(33).} \mathrm{The} \mathrm{expression} \mathrm{of} 5 \mathrm{hmC}$ in many tumor tissues was found to be significantly reduced compared with that in normal tissues. According to a recent report (34), the expression of $5 \mathrm{hmC}$ in pancreatic, liver, lung, prostate and breast cancer tissues was lower than that in normal tissues, thus acting as a biological indicator for the detection of tumors. In the present study, a dot-blot assay indicated that $40 \mu \mathrm{M}$ emodin and $1 \mu \mathrm{M} 5$-Aza-CdR significantly reduced the $5 \mathrm{mC}$ expression, but showed no significant change in the expression of $5 \mathrm{hmC}$. Therefore, our study indicates that emodin can reduce the generation of $5 \mathrm{mC}$ by inhibiting the expression of DNMT. These results are consistent with the above results from PCR and western blotting. However, as $5 \mathrm{mC}$ is catalyzed by TET to generate $5 \mathrm{hmC}$, emodin may have no effect on the expression and activity of TET enzymes.

In summary, BSP demonstrated that emodin, to a certain degree, affected the demethylation of tumor-suppressor genes P16, RASSF1A, and ppENK in the pancreatic cancer cell line PANC-1. RT-PCR and western blot results showed that emodin caused the re-expression of P16, RASSF1A and ppENK which were previously not expressed or weakly expressed in the PANC-1 cells. Emodin also reduced the expression of DNMT1 and DNMT3a. The dot-blot results confirmed that emodin reduced the expression of the $5 \mathrm{mC}$ genome, likely by inhibiting the expression of DNMT. This discovery provides a novel strategy for the treatment of pancreatic cancer. Clinical treatment of emodin in pancreatic cancer occurs not only through apoptosis or inhibition of angiogenesis but also through demethylation in epigenetics.

\section{Acknowledgements}

We are grateful for the financial support from the Jiaxing Science and Technology Projects (grant no. 2013AY21042-5) and Jiaxing Science and Technology innovation team project (grant no. 2013-03).

\section{References}

1. Reske SN: PET and PET-CT of malignant tumors of the exocrine pancreas. Radiologe 49: 131-136, 2009 (In German).

2. Hariharan D, Saied A and Kocher HM: Analysis of mortality rates for pancreatic cancer across the world. HPB Oxf 10: 58-62, 2008.

3. Guo X and Cui Z: Current diagnosis and treatment of pancreatic cancer in China. Pancreas 31: 13-22, 2005.

4. Cheng X and Blumenthal RM: Mammalian DNA methyltransferases: a structural perspective. Structure 16: 341-350, 2008.

5. Bird A: DNA methylation patterns and epigenetic memory. Genes Dev 16: 6-21, 2002.

6. Gambichler T, Sand M and Skrygan M: Loss of 5-hydroxymethylcytosine and ten-eleven translocation 2 protein expression in malignant melanoma. Melanoma Res 23: 218-220, 2013.

7. Matsuoka S, Edwards MC, Bai C, Parker S, Zhang P, Baldini A, Harper JW and Elledge SJ: p5 $7^{\mathrm{KIP} 2}$, a structurally distinct member of the $\mathrm{p} 21^{\mathrm{CIPl}} \mathrm{Cdk}$ inhibitor family, is a candidate tumor suppressor gene. Genes Dev 9: 650-662, 1995.

8. Sato N, Fukushima N, Maehara N, Matsubayashi H, Koopmann J, Su GH, Hruban RH and Goggins M: SPARC/osteonectin is a frequent target for aberrant methylation in pancreatic adenocarcinoma and a mediator of tumor-stromal interactions. Oncogene 22: 5021-5030, 2003.

9. Attri J, Srinivasan R, Majumdar S, Radotra BD and Wig J: Alterations of tumor suppressor gene P16INK4a in pancreatic ductal carcinoma. BMC Gastroenterol 5: 22, 2005.

10. Dammann R, Schagdarsurengin U, Liu L, Otto N, Gimm O, Dralle H, Boehm BO, Pfeifer GP and Hoang-Vu C: Frequent RASSF1A promoter hypermethylation and K-ras mutations in pancreatic carcinoma. Oncogene 22: 3806-3812, 2003.

11. Ueki T, Toyota M, Skinner H, Walter KM, Yeo CJ, Issa JP, Hruban RH and Goggins M: Identification and characterization of differentially methylated $\mathrm{CpG}$ islands in pancreatic carcinoma. Cancer Res 61: 8540-8546, 2001.

12. Fukushima N, Sato N, Ueki T, Rosty C, Walter KM, Wilentz RE, Yeo CJ, Hruban RH and Goggins M: Aberrant methylation of preproenkephalin and P16 genes in pancreatic intraepithelial neoplasia and pancreatic ductal adenocarcinoma. Am J Pathol 160: 1573-1581, 2002.

13. Schutte M, Hruban RH, Geradts J, Maynard R, Hilgers W, Rabindran SK, Moskaluk CA, Hahn SA, Schwarte-Waldhoff I, Schmiegel W, et al: Abrogation of the Rb/P16 tumor-suppressive pathway in virtually all pancreatic carcinomas. Cancer Res 57: 3126-3130, 1997

14. Moore PS, Sipos B, Orlandini S, Sorio C, Real FX, Lemoine NR, Gress T, Bassi C, Klöppel G, Kalthoff H, et al: Genetic profile of 22 pancreatic carcinoma cell lines. Analysis of K-ras, p53, P16 and DPC4/Smad4. Virchows Arch 439: 798-802, 2001.

15. Brueckner B, Kuck D and Lyko F: DNA methyltransferase inhibitors for cancer therapy. Cancer J 13: 17-22, 2007.

16. Szyf M: DNA methylation and demethylation as targets for anticancer therapy. Biochemistry (Mosc) 70: 533-549, 2005.

17. Goffin $\mathrm{J}$ and Eisenhauer E: DNA methyltransferase inhibitors state of the art. Ann Oncol 13: 1699-1716, 2002.

18. Lyko F and Brown R: DNA methyltransferase inhibitors and the development of epigenetic cancer therapies. J Natl Cancer Inst 97: 1498-1506, 2005. 
19. Xiang N, Zhao R, Song G and Zhong W: Selenite reactivates silenced genes by modifying DNA methylation and histones in prostate cancer cells. Carcinogenesis 29: 2175-2181, 2008.

20. Brueckner B, Garcia Boy R, Siedlecki P, Musch T, Kliem HC, Zielenkiewicz P, Suhai S, Wiessler M and Lyko F: Epigenetic reactivation of tumor suppressor genes by a novel small-molecule inhibitor of human DNA methyltransferases. Cancer Res 65: 6305-6311, 2005.

21. Cui X, Wakai T, Shirai Y, Yokoyama N, Hatakeyama K and Hirano S: Arsenic trioxide inhibits DNA methyltransferase and restores methylation-silenced genes in human liver cancer cells. Hum Pathol 37: 298-311, 2006.

22. Lin SZ, Chen KJ, Tong HF, Jing H, Li H and Zheng SS: Emodin attenuates acute rejection of liver allografts by inhibiting hepatocellular apoptosis and modulating the Th1/Th2 balance in rats. Clin Exp Pharmacol Physiol 37: 790-794, 2010.

23. Li HL, Chen HL, Li H, Zhang KL, Chen XY, Wang XW, Kong QY and Liu J: Regulatory effects of emodin on NF- $\kappa \mathrm{B}$ activation and inflammatory cytokine expression in RAW 264.7 macrophages. Int J Mol Med 16: 41-47, 2005.

24. Li-Weber M: Targeting apoptosis pathways in cancer by Chinese medicine. Cancer Lett 332: 304-312, 2013.

25. Liu A, Chen H, Tong H, Ye S, Qiu M, Wang Z, Tan W, Liu J and Lin S: Emodin potentiates the antitumor effects of gemcitabine in pancreatic cancer cells via inhibition of nuclear factor- $\kappa \mathrm{B}$. Mol Med Rep 4: 221-227, 2011.

26. Liu Z, Xie Z, Jones W, Pavlovicz RE, Liu S, Yu J, Li PK, Lin J, Fuchs JR, Marcucci G, et al: Curcumin is a potent DNA hypomethylation agent. Bioorg Med Chem Lett 19: 706-709, 2009.

27. Fang MZ, Wang Y, Ai N, Hou Z, Sun Y, Lu H, Welsh W and Yang CS: Tea polyphenol (-)-epigallocatechin-3-gallate inhibits DNA methyltransferase and reactivates methylation-silenced genes in cancer cell lines. Cancer Res 63: 7563-7570, 2003.
28. Xu W, Yang H, Liu Y, Yang Y, Wang P, Kim SH, Ito S, Yang C, Wang P, Xiao MT, et al: Oncometabolite 2-hydroxyglutarate is a competitive inhibitor of $\alpha$-ketoglutarate-dependent dioxygenases. Cancer Cell 19: 17-30, 2011.

29. Lin SZ, Wei WT, Chen H, Chen KJ, Tong HF, Wang ZH, Ni ZL, Liu HB, Guo HC and Liu DL: Antitumor activity of emodin against pancreatic cancer depends on its dual role: promotion of apoptosis and suppression of angiogenesis. PLoS One 7: e42146, 2012.

30. Liu A, Luo J and Zhang JH: Emodin combined gemcitabine inhibited the growth of pancreatic cancer in vitro and in vivo and its mechanisms study. Zhongguo Zhong Xi Yi Jie He Za Zhi 32: 652-656, 2012 (In Chinese).

31. Chen H, Wei W, Guo Y, Liu A, Tong H, Wang Z, Tan W, Liu J and Lin S: Enhanced effect of gemcitabine by emodin against pancreatic cancer in vivo via cytochrome C-regulated apoptosis. Oncol Rep 25: 1253-1261, 2011.

32. Tahiliani M, Koh KP, Shen Y, Pastor WA, Bandukwala H, Brudno Y, Agarwal S, Iyer LM, Liu DR, Aravind L, et al: Conversion of 5-methylcytosine to 5-hydroxymethylcytosine in mammalian DNA by MLL partner TET1. Science 324: 930-935, 2009.

33. Wu SC and Zhang Y: Active DNA demethylation: many roads lead to Rome. Nat Rev Mol Cell Biol 11: 607-620, 2010.

34. Yang H, Liu Y, Bai F, Zhang JY, Ma SH, Liu J, Xu ZD, Zhu HG, Ling ZQ, Ye D, et al: Tumor development is associated with decrease of TET gene expression and 5-methylcytosine hydroxylation. Oncogene 32: 663-669, 2013. 